AperTO - Archivio Istituzionale Open Access dell'Università di Torino

Chemotherapy in non-small cell lung cancer patients after prior immunotherapy: The multicenter retrospective CLARITY study

This is a pre print version of the following article:

Original Citation:

Availability:

This version is available http://hdl.handle.net/2318/1770053

since 2021-01-29T16:00:46Z

Published version:

DOI:10.1016/j.lungcan.2020.10.008

Terms of use:

Open Access

Anyone can freely access the full text of works made available as "Open Access". Works made available under a Creative Commons license can be used according to the terms and conditions of said license. Use of all other works requires consent of the right holder (author or publisher) if not exempted from copyright protection by the applicable law. 


\section{Chemotherapy in Non-Small cell Lung Cancer patients AfteR prior ImmunoTherapY: the multicenter retrospective CLARITY study}

Melissa Bersanelli ${ }^{\S 1,2}$, Sebastiano Buti ${ }^{2}$, Diana Giannarelli ${ }^{3}$, Alessandro Leonetti ${ }^{1,2}$, Alessio Cortellini ${ }^{4,5}$, Giuseppe Lo Russo ${ }^{6}$, Diego Signorelli ${ }^{6}$, Luca Toschi ${ }^{7}$, Michele Milella ${ }^{8}$, Sara Pilotto ${ }^{8}$, Emilio Bria ${ }^{9}$, Claudia Proto $^{6}$, Anna Mariniello ${ }^{7}$, Giovanni Randon ${ }^{6}$, Sabrina Rossi ${ }^{7}$, Emanuele Vita ${ }^{9}$, Giulia Sartori ${ }^{8}$, Ettore D’Argento $^{9}$, Eva Qako ${ }^{1}$, Elisa Giaiacopi ${ }^{1}$, Laura Ghilardi ${ }^{10}$, Anna Cecilia Bettini ${ }^{10}$, Elena Rapacchi ${ }^{2}$, Francesca Mazzoni $^{11}$, Daniele Lavacchi ${ }^{1}$, Vieri Scotti ${ }^{12}$, Lucia Pia Ciccone ${ }^{12}$, Michele De Tursi ${ }^{13}$, Pietro Di Marino ${ }^{13}$, Daniele Santini ${ }^{14}$, Marco Russano ${ }^{14}$, Paola Bordi ${ }^{2}$, Massimo Di Maio ${ }^{15}$, Marco Audisio ${ }^{15}$, Marco Filetti ${ }^{16}$, Raffele Giusti ${ }^{16}$, Rossana Berardi ${ }^{17}$, Ilaria Fiordoliva ${ }^{17}$, Giulio Cerea ${ }^{18}$, Elio Gregory Pizzutilo ${ }^{18}$, Alessandra Bearz $^{19}$, Elisa De Carlo ${ }^{19}$, Fabiana Cecere $^{20}$, Davide Renna $^{20}$, Roberta Camisa ${ }^{2}$, Giuseppe Caruso ${ }^{2}$, Corrado Ficorella ${ }^{4,5}$, Giuseppe Luigi Banna ${ }^{21}$, Diego Cortinovis ${ }^{22}$, Matteo Brighenti ${ }^{23}$, Marina Chiara Garassino ${ }^{6}$ and Marcello Tiseo ${ }^{1,2}$.

${ }^{1}$ Medicine and Surgery Department, University of Parma, Parma, Italy

${ }^{2}$ Medical Oncology Unit, University Hospital of Parma, Parma, Italy

${ }^{3}$ Regina Elena National Cancer Institute, IRCCS, Biostatistical Unit, Rome, Italy

${ }^{4}$ Department of Biotechnology and Applied Clinical Science, University of L'Aquila, L'Aquila, Italy.

${ }^{5}$ Medical Oncology, St. Salvatore Hospital, L'Aquila, Italy.

${ }^{6}$ Oncologia Toracica, Dipartimento di Oncologia Medica, Fondazione IRCCS Istituto Nazionale dei Tumori di Milano, Italy

${ }^{7}$ Medical Oncology, Humanitas Clinical and Research Center - IRCCS, Rozzano, Milano, Italy

${ }^{8}$ Section of Oncology, Department of Medicine, University of Verona School of Medicine and Verona University Hospital Trust, Verona, Italy

${ }^{9}$ Comprehensive Cancer Center, Fondazione Policlinico Universitario Agostino Gemelli IRCCS, and Dipartimento di Medicina e Chirurgia Traslazionale, Università Cattolica del Sacro Cuore, Roma, Italy

${ }^{10}$ UO di Oncologia medica, ASST PAPA Giovanni XXIII Bergamo, Italy

${ }^{11}$ Oncology Department, Careggi University Hospital, Firenze, Italy

${ }^{12}$ Radiation Oncology Unit, Oncology Department, Azienda Ospedaliero-Universitaria Careggi, Firenze, Italy 
${ }^{13}$ Dipartimento di Scienze orali e mediche, Sezione di Oncologia, Università G. D'Annunzio, Chieti, Italy ${ }^{14}$ Oncologia, Policlinico Universitario Campus Biomedico, Roma, Italy.

${ }^{15}$ Department of Oncology, University of Turin; AO Ordine Mauriziano Hospital, Torino.

${ }^{16}$ Medical Oncology Unit, Azienda Ospedaliero-Universitaria Sant'Andrea, Roma, Italy

${ }^{17}$ Clinica Oncologica, Università Politecnica delle Marche - Ospedali Riuniti, Ancona, Italy

${ }^{18}$ Ospedale Niguarda, Oncologia, Milano, Italy

${ }^{19}$ Centro di Riferimento Oncologico, CRO-IRCCS, Aviano, Italy

${ }^{20}$ Regina Elena National Cancer Institute, IRCCS, Oncology Unit, Rome, Italy

${ }^{21}$ Portsmouth Hospitals NHS Trust, Portsmouth, UK.

${ }^{22}$ SC Oncologia/SS Lung Unit Asst H S Gerardo, Monza, Italy

${ }^{23}$ Medical Oncology Department, ASST Cremona, Cremona, Italy.

$\S$ Correspondence to: Dr. Melissa Bersanelli, Medical Oncology Unit, University Hospital of Parma, Via Gramsci 14, 43126 Parma, Italy, telephone: +39 0521 702314, e-mail: bersamel@libero.it 


\section{Abstract}

Objectives: In the most of cases, for non-small cell lung cancer (NSCLC) patients who progressed to previous immune checkpoint inhibitors (CKI) administered as first- or as second-line therapy, chemotherapy (CT) remains the only viable options in the absence of "druggable" mutations. We aimed to explore the efficacy of salvage chemotherapy after immunotherapy (SCAI) in advanced NSCLC patients.

Materials and Methods: We designed a retrospective, multicenter study, involving 20 Italian centers, with the primary objective of describing the clinical outcome of advanced NSCLC patients treated with SCAI at the participating institutions from November 2013 to July 2019. The primary endpoint of the study was represented by overall survival (OS), defined as the time from CT initiation to death. Secondary outcome endpoints of the SCAI (progression free survival, PFS, and objective response rate, ORR and toxicity) and explorative biomarkers (lactate dehydrogenase, LDH, and neutrophil-to-lymphocyte ratio, NLR during immunotherapy) were also analyzed.

Results: In our study population of 342 NSCLC patients, SCAI had a median OS of 6.8 months (95\% confidence interval, $\mathrm{Cl} 5.5-8.1)$, median PFS of 4.1 months ( $95 \% \mathrm{Cl} 3.4-4.8)$ and ORR of $22.8 \%$. A "Post-CKI score" was constructed by combining significant predictors of OS at the multivariate analyses (sex, ECOG PS, disease control with prior immunotherapy), Harrell'C was 0.65, (95\% $\mathrm{Cl}: 0.59-0.71)$.

Conclusions: Despite the late-line settings, our findings support the hypothesis that previous immunotherapy might increase the sensitivity of the tumor to the subsequent chemotherapy. The "Post-CKI score" was clinically effective in successfully discriminating three distinct prognostic subgroups of patients after the failure of CKI, representing a possibly useful tool for the tailored decision-making process of advanced treatment-line settings in NSCLC. 


\title{
Keywords
}

NSCLC, CLARITY, chemotherapy after immunotherapy, salvage chemotherapy, immune checkpoint inhibitors

\author{
Abbreviations: \\ $\mathrm{CKI}=$ immune checkpoint inhibitors \\ PD-1 = programmed cell death 1 \\ PD-L1 = programmed death ligand 1 \\ NSCLC = non-small cell lung cancer \\ $\mathrm{CT}=$ chemotherapy \\ SCAI = salvage chemotherapy after immunotherapy \\ $\mathrm{ORR}=$ objective response rate \\ $\mathrm{LCBI}=$ last chemotherapy administered before immunotherapy \\ NLR = neutrophil-to-lymphocyte ratio \\ $A N C=$ absolute neutrophil count \\ OS = overall survival \\ PFS $=$ progression free survival \\ $\mathrm{LDH}=$ lactate dehydrogenase \\ $\mathrm{Cl}=$ confidence interval \\ $\mathrm{HR}=$ hazard ratio
}

ECOG PS = Eastern Cooperative Oncology Group performance status

mOS $=$ median overall survival

$D C R=$ disease control rate

mPFS = median progression-free survival 


\section{Introduction}

Immune checkpoint inhibitors (CKI) such as anti-programmed cell death 1 (PD-1) or antiprogrammed death ligand 1 (PD-L1) agents have rapidly been established as a standard of care in advanced non-small cell lung cancer (NSCLC) patients, both in the second-line setting (nivolumab, pembrolizumab and atezolizumab) and more recently in the first-line setting. After prior approval of pembrolizumab monotherapy for NSCLC patients with tumor cell PD-L1 immunohistochemical expression $\geq 50 \%$, treatment with CKI has been introduced in the first-line strategy also for lower PD-L1 expression levels, in this case combined with standard chemotherapy (CT) [1]. In the most of cases, for patients who progressed to previous CKI in first-line or in second-line, chemotherapy, when feasible, remains the only viable options in the absence of "druggable" mutations. In this sense, the issue of the efficacy of salvage CT after immunotherapy (SCAI) has recently arisen and is currently being explored $[2,3]$.

A retrospective study recently compared the objective response rates (ORR) of SCAI with the ORR of the last CT administered before immunotherapy (LCBI) in a population of 73 advanced NSCLC patients treated with anti-PD-1/PD-L1 inhibitors, showing a superior ORR of SCAI compared to that of LCBI in the same cohort. Nevertheless, these results did not translate into a progression-free survival (PFS) benefit. In addition, no differences in terms of ORR of SCAI were observed according to the duration of prior PD-1/PD-L1 inhibitor therapy [2].

Another smaller retrospective study explored the efficacy of single-agent CT (third-line or beyond), in terms of ORR, when administered after exposure to previous therapy with anti-PD1 agents in 28 patients with metastatic NSCLC. All patients had received at least one treatment line before immunotherapy, always represented by platinum-based CT, and none of them experienced an objective response to immunotherapy. Interestingly, CT achieved a slightly superior ORR when administered after immunotherapy, compared to CT prior to CKI (ORR: $39 \%$ vs $37 \%$, respectively), 
suggesting that anti-PD1 may confer delayed synergism to subsequent cytotoxic therapy [3]. Taken together, these evidences indicate that CKI may enhance efficacy of the following cytotoxic agent.

Current research is also focusing on the identification of putative circulating predictive biomarkers of response to $\mathrm{CT}$, when administered after CKI. In this regard, early dynamics of neutrophil-tolymphocyte ratio (NLR) and absolute neutrophil count (ANC) during nivolumab treatment have been associated with the efficacy of subsequent salvage chemotherapy in NSCLC patients [4].

Considering the interesting but very limited literature in the field, we planned a retrospective study with the aim of describing the clinical outcome of NSCLC patients treated with CT after failure of previous immunotherapy. Moreover, we explored the possible role of laboratory parameters acquired during immunotherapy in predicting the outcome of patients to the subsequent CT.

\section{Materials and Methods}

We designed a retrospective, multicenter study, involving 20 Italian centers, with the primary objective of describing the clinical outcome of advanced NSCLC patients treated with SCAI.

Inclusion criteria were: age $\geq 18$ years; diagnosis of metastatic NSCLC; previous treatment with anti-PD-1/anti-PD-L1 CKI at any treatment line; at least one administration of SCAI, from November 2013 to July 2019. Exclusion criteria were concomitant synchronous metastatic malignancies aside from NSCLC; further therapies received between CKI and CT (eg. targeted drugs or other non-immunotherapeutic agents). 
The primary endpoint of the study was represented by overall survival (OS), defined as the time from CT initiation to death. PFS and ORR (according to RECIST 1.1 criteria) and toxicity of treatment (defined according to CTCAE version 5) have been investigated as secondary endpoints. As exploratory co-endpoints, we measured the levels of lactate dehydrogenase (LDH), calcium, albumin, leukocytes, hemoglobin, neutrophils, lymphocytes, NLR, platelets and their trend during immunotherapy, considering the basal values and at least a subsequent value, and correlated their trend to clinical outcomes.

The sample size was based on the population of patients expected to meet the inclusion criteria at the participating centers. Based on feasibility, the number of patients expected to be included was around 250 patients. This sample size would have allowed to estimate the percentage of OS at one year, expected to be around $30 \%$ based on previous published data $[5,6]$, with a standard error inferior to 3\%. Every associations were tested exclusively in a "hypotheses generating" perspective.

Data from clinical records of patients were anonymized, collected, and then analyzed for the study purpose. All data about the clinical history of patients, including demographics and comorbidities, diagnosis and treatment of NSCLC, outcome to CKI treatment and to the subsequent CT, were collected. Data about the levels of LDH, calcium, albumin, leukocytes, hemoglobin, neutrophils, lymphocytes, NLR, platelets were collected from clinical records at two time-points: the basal time (at the immunotherapy initiation) and subsequently during immunotherapy, conventionally immediately before the second administration of CKI. Only for LDH values, they were also collected at the time of the disease progression to CKI, before initiating CT.

Demographic variables and outcome measures have been reported using descriptive statistics. Survival curves have been estimated with the Kaplan-Meier method and compared using log-rank 
test. Median survival times were reported along with their $95 \%$ confidence intervals $(95 \% \mathrm{Cl})$. Median follow-up times were estimated with the reverse method. Cox regression model was used to estimate hazard ratios $(\mathrm{HR})$ and their $95 \% \mathrm{Cl}$. Variables mostly associated with OS were selected using a stepwise forward method, based on Wald statistics. A prognostic score for OS was built considering each significant variable to which a weight proportional to its regression $\beta$ coefficient was assigned. Coefficients were rounded up for an easier calculation. Harrell's C test was used to assess the goodness of calibration of the model.

The coordinators of this study guarantee under their responsibility that the study was conducted in accordance with the Helsinki Declaration and subsequent updates. An informed consent was obtained when applicable. The protocol was approved by the Local Ethics Committees of the participating centers in compliance with the national legislation.

\section{Results}

\section{Patient characteristics and outcome to chemotherapy}

The overall study population included 342 patients who received SCAI, from November 2013 to July 2019.

Patient characteristics at the time of CT initiation are reported in Table 1. Median age was 66 years (range 34-86); most of patients were male (61.4\%), 22.5\% had Eastern Cooperative Oncology Group performance status (ECOG PS) of 2, and histology was adenocarcinoma in the majority of patients (71\%). SCAI was administered in second line in 86 cases (25.1\%), in third line in 197 cases (57.6\%) and as fourth or further lines in 59 cases (17.3\%). Median follow-up time from CT initiation was 10.7 months $(95 \% \mathrm{Cl} 7.5-13.9)$. The majority of patients (38.9\%) received a taxane-based 
chemotherapy across different lines. Among 86 patients who were treated with SCAI in secondline, 67 (78\%) received a platinum-based doublet.

Median OS (mOS) from CT was 6.8 months in the overall population (95\% Cl 5.5-8.1) (Figure 1a). At the univariate analyses (Table 2), females had mOS of 9.5 months (95\% $\mathrm{Cl} 7.6-11.3$ ), significantly longer than that of males, of 5.7 months ( $95 \% \mathrm{Cl} 4.9-6.5)$, with $\mathrm{HR} 0.69(95 \% \mathrm{Cl} 0.52-$ 0.92), $p=0.01$. Disease control rate (DCR) to prior immunotherapy was associated with better survival to subsequent CT: mOS was 8.3 months (95\% Cl 5.9-10.6) for patients with partial or complete response or stable disease to ICl vs 5.7 months ( $95 \% \mathrm{Cl} 4.8-6.6$ ) for patients with disease progression as best response to ICl (HR 0.68 [95\% Cl 0.52-0.89], $p=0.005)$. Good ECOG PS was significantly related to improved OS $(p=0.0001)$ : patients with an ECOG PS of 2 had a significantly shorter mOS than that of patients with ECOG PS 0 (3.0 months vs 11.4 months, HR $3.80(95 \% \mathrm{Cl}$ 2.39-6.03), $p<0.0001$ ). These variables were confirmed to be related to mOS at the multivariate analysis, with HR 1.54 (95\% Cl 1.15-2.06), $p=0.004$ for the gender in favor of females, HR 3.93 (95\% Cl 2.47-6.26), $p<0.0001$ in favor of PS 0 compared to PS 2, and HR $0.68(0.52-0.90), p=0.006$ in favor of patients who achieved disease control with the prior immunotherapy, respectively (Table 3).

Further variables were related to better OS from SCAI at the univariate analyses, such as the smoking status, favoring former smokers vs never smokers $(p=0.03)$; ORR at prior immunotherapy, favoring responders vs non-responders $(p=0.01)$; NLR at immunotherapy initiation, favoring patients with NLR $<4$ vs patients with NLR $\geq 4(p=0.014)$; PFS at prior immunotherapy, favoring patients with PFS $\geq 4$ months vs patients with PFS $<4$ months $(p=0.007)$ and receiving a platinum-based combination vs other types of chemotherapy $(p=0.03)$. Nevertheless, none of them were confirmed at the multivariate analyses (except for NLR, not included in the multivariate analysis due to the not complete availability of data for all patients). 
Median PFS (mPFS) to chemotherapy was 4.1 months (95\% Cl 3.4-4.8), (Figure 1b). At the univariate analyses (Table 2), DCR to prior immunotherapy was associated with better PFS to SCAI, with mPFS of 4.6 months $(95 \% \mathrm{Cl} 3.9-5.2)$ for patients with partial or complete response to $\mathrm{ICl}$ vs 2.9 months $(95 \% \mathrm{Cl} 2.1-5.2)$ for patients with disease progression as best response to ICI [HR 0.73 (95\% Cl 0.56-0.94), $p=0.01$ ]. Moreover, ECOG PS was related to improved PFS $(p<0.0001)$, especially in the case of PS 2 vs 0 , with mPFS of 2.1 months ( $95 \% \mathrm{Cl} 1.8-2.4)$ vs 5.7 months $(95 \% \mathrm{Cl}$ 4.7-6.7) respectively [HR $2.29(95 \% \mathrm{Cl} 1.53-3.43), p<0.0001]$. Patients who had toxicity from CT had better PFS than those without toxicity [HR 0.70 (95\% $\mathrm{Cl} 0.54-0.90), p=0.006$ ]. These three variables were confirmed at the multivariate analyses as having an impact on PFS, respectively with HR 0.76 (95\% Cl 0.59-0.99), $p=0.04$ in favor of patients with DCR at prior immunotherapy, HR $2.13(95 \% \mathrm{Cl} 1.40-3.22), p=0.0001$ in favor of PS 0 compared to PS 2, and HR 0.75 (95\% Cl 0.580.98), $p=0.036$ favoring patients with toxicity to CT (Table 3).

Further variables were related to PFS to SCAI at the univariate analyses, were LDH at chemotherapy initiation, in favor of patients with values $<250 \mathrm{U} / \mathrm{I}(p=0.02) v s \geq 250 \mathrm{U} / \mathrm{I}$ and PFS to prior immunotherapy, favoring patients with PFS $\geq 4$ months $v s<4$ months $(p=0.03)$.

The ORR to CT was $22.8 \%$ (77 partial responses and 1 complete response); $40.6 \%$ of patients were primary refractory to SCAI and $22.8 \%$ had stable disease as their best response (DCR was $45.6 \%$ ); $13.7 \%$ were not evaluable, mostly due to clinical progression and death before the radiological assessment. None of the variables explored among gender, smoking status, type of CT, toxicity to $\mathrm{CT}$, type of prior CKI drug, treatment line and ORR and PFS to prior immunotherapy, were related to $\mathrm{ORR}$ ( $p=$ NS in all cases).

\section{"Post-CKI" prognostic score}


By combining the three factors which remained significant at the multivariate analyses for OS, we created a prognostic "Post-CKI" score based on regression $\beta$ coefficients as follows: patients were given zero point for each of female sex, ECOG PS of 0 , disease control with prior immunotherapy (reference category for each item); one point for each of male sex, ECOG PS of 1, lack of disease control with prior immunotherapy; two points for ECOG PS of 2 . The aim of the score was the prediction of survival probability prior to offering CT to advanced NSCLC patients progressed to ICI immunotherapy. As a result of this process, the score ranged from 0 (best prognosis) to 4 (worst prognosis). We then used a three-risk group stratification as follows: score 0-1 (good prognosis), score 2 (intermediate prognosis), score 3-4 (poor prognosis). Harrell'C was 0.65, (95\% Cl:0.590.71). The OS curves, according to the score stratification, are shown in Figure 2.

\section{Survival outcome of the treatment sequence}

We calculated the outcome measures of the treatment sequence of immunotherapy followed by chemotherapy, namely OS-2. Patient characteristics at the time of immunotherapy initiation are reported in Supplementary Table S1.

Overall, the median follow-up time from ICl start was 22.4 months (95\% Cl 19.8-25.0). Median OS2 was 15.2 months in the overall population (95\% $\mathrm{Cl} 13.7-16.6$, Figure 3 ). At the univariate analyses, the correlations with ECOG PS and with DCR were maintained, aside from other variables

related to OS-2 showed in the Supplementary Table S2. Of note, having NLR $\geq 4$ at immunotherapy initiation and at CT initiation were factors both related to worse OS-2 ( $p=0.008$ and $p=0.003$ respectively).

\section{Discussion}


The advanced-line setting has been historically considered a stumbling block in the treatment of NSCLC, both for patients and clinicians. Second-line single agent CT achieved poor clinical outcomes in clinical trials. Indeed, in this setting, ORR ranges from $7.1 \%$ to $15.5 \%$, mPFS from 2.6 to 2.9 months and mOS from 7.0 to 8.3 months [7-9]. Moreover, a combination strategy based on the addition of carboplatin to pemetrexed did not improve survival outcomes in the second-line setting compared to pemetrexed monotherapy [10]. A recent systematic review of real-world observational studies reported mOS range of 4.6-12.8 months for the second-line setting and 2.812.0 months for the third-line setting [11].

In our study, SCAl granted a mPFS of 4.1 months $(95 \% \mathrm{Cl} 3.4-4.8)$ and a mOS of 6.8 months $(95 \% \mathrm{Cl}$ 5.5-8.1). Considering that our cohort was mostly made of patients treated in the third-line setting (57.6\%) and included a not negligible portion of patients from the fourth/further-line setting, our results are at least aligned to those above-mentioned. Consistently with previous reports [12], both mOS and MPFS were higher in patients who achieved disease control with prior CKI than in those who did not. These findings were furtherly confirmed at the multivariate analysis (mOS and mPFS significantly in favor of patients obtaining disease control with prior immunotherapy).

Among different patient characteristics, female sex, ECOG PS of 0 , and disease control to prior immunotherapy were significantly related to better OS at the multivariate analysis. Interestingly, when patients were stratified according to the "Post-CKI" score, we effectively identified three different risk groups for survival (Harrell'C: 0.65). In turn, only DCR and ECOG PS were related to PFS, suggesting a possible predictive role beyond their prognostic value.

Recently, Kato and collaborators reported the results of a propensity score-weighted analysis to investigate the efficacy of CT after PD-1 inhibitor vs CT alone in 1439 advanced NSCLC individuals. The authors revealed that patients who received CT after previous anti-PD-1 therapy (243 patients) achieved a higher ORR (18.9\%) compared to patients who received CT in the lack of 
previous exposure to anti PD-1 agents (11.0\%). These results were in spite of the disproportion between the two arms, being most of the patients within the post-CKI cohort in the third-line setting, while most of the patients treated with CT alone were in the second-line setting [13]. Interestingly, we reported a ORR of $22.8 \%$ in our cohort, across different lines of therapy, which appears considerably high if compared to the ORR reported in clinical trials in the advanced setting [7-9]. Not least, the ORR of our cohort was consistent with ORRs previously reported for CT in the post-immunotherapy setting $[2-3,12]$, strengthening the hypothesis that previous exposure to a CKI might elicit the anti-tumor activity of CT [14]. One explanation could rely in the increased pool of activated T lymphocytes after immunotherapy, which can lead to high response rates. In addition, as already postulated, the antibody levels of CKI might still be present at the time of CT administration, due to the long half-life of CKIs [3], thus acting in a synergic manner [15].

When looking at the correlation between circulating biomarkers and benefit of SCAI, NLR $\geq 4$ at immunotherapy initiation was related to worse OS ( $p=0.014)$. NLR $\geq 4$ at immunotherapy initiation and CT initiation were both related to worse OS-2 ( $p=0.008$ and $p=0.003$ respectively). These findings furtherly support the prognostic role of NLR in advanced NSCLC patients receiving systemic treatments [16]. In addition, they suggest the long-term reliability of NLR, which prognostic value seems long-lasting from the initiation of CKI until the outcome to the subsequent CT.

We also explored the correlation of tumor PD-L1 expression and response to SCAI. However, as in the study of Kato and colleagues [13], we did not find any significant association between clinical outcomes and PD-L1 expression (Table 2).

Focusing on the OS-2 analysis, we found that the treatment line is one of the major determinants for survival in the post-CKI scenario. Despite the lack of statistical significance, we observed an increased benefit for patients who received SCAI in second line. Furthermore, patients who 
received platinum-based doublets achieved the highest ORR and DCR (most of them probably receiving them as second-line treatment). To further strengthen these results, a recent analysis of second-line treatment outcomes after first-line immunotherapy confirmed that patients who received platinum-based doublets achieved longer OS compared to other treatment options [17]. Even though direct comparisons were not the aim of this study, based on our results, we could speculate that second line might be the best setting of administration of SCAI, and that platinumbased doublet might be the preferred option after failure of CKI therapy. However, the choice of a second-line $\mathrm{CT}$, in the limited subgroup of patients currently candidate to receive first-line anti-PD1 monotherapy, might be influenced by the overall clinical conditions of the patients, favoring a platinum-based doublet only in selected "platinum-fit" cases, with good ECOG PS.

Due to the rapidly evolving scenario of advanced NSCLC treatment, we must recognize that, currently, the majority of NSCLC patients might receive CT combined with first-line immunotherapy. In this context, the efficacy of CT after previous combination of chemoimmunotherapy is still to be investigated.

Our study is limited by the retrospective nature and by the lack of complete data about circulating biomarkers for all patients, not allowing the inclusion of such factors in the multivariate analyses.

\section{Conclusions}

An increasing portion of advanced NSCLC patients is currently reaching the advanced setting (second line and more), thanks to the recent advances in the field. Despite promising activity of novel CKIs, the vast majority of patients will experience progression of disease and might be candidate to a subsequent CT. In our study, we reported a promising activity of SCAl, supporting the hypothesis that a previous immunotherapy might increase the sensitivity of the tumor to the subsequent CT. Prior response to $\mathrm{CKI}$ might have a predictive role towards the outcome of 
patients to SCAI. Our "Post-ICI score", despite the relatively modest statistical power, is clinically effective in successfully discriminating three distinct prognostic subgroups of patients after failure of CKI, and might be used by the clinicians as a tool for the tailored decision-making process of advanced-line settings. 


\section{References}

1. D. Planchard, S. Popat, K. Kerr, S. Novello, E.F. Smit, C. Faivre-Finn, T.S. Mok, M. Reck, P.E. Van Schil, M.D. Hellmann, S. Peters, Metastatic non-small cell lung cancer: ESMO Clinical Practice Guidelines for diagnosis, treatment and follow-up, Ann. Oncol. 29 (2018) iv192-iv237. https://doi.org/10.1093/annonc/mdy275.

2. S.E. Park, S.H. Lee, J.S. Ahn, M.J. Ahn, K. Park, J.M. Sun, Increased Response Rates to Salvage Chemotherapy Administered after PD-1/PD-L1 Inhibitors in Patients with NonSmall Cell Lung Cancer, J. Thorac. Oncol. 13 (2018) 106-111. https://doi.org/10.1016/j.jtho.2017.10.011.

3. G. Schvartsman, S.A. Peng, G. Bis, J.J. Lee, M.F.K. Benveniste, J. Zhang, E.B. Roarty, L. Lacerda, S. Swisher, J. V. Heymach, F. V. Fossella, W.N. William, Response rates to single-agent chemotherapy after exposure to immune checkpoint inhibitors in advanced non-small cell lung cancer, Lung Cancer. 112 (2017) 90-95. https://doi.org/10.1016/j.lungcan.2017.07.034.

4. H. Soda, D. Ogawara, Y. Fukuda, H. Tomono, D. Okuno, S. Koga, H. Taniguchi, M. Yoshida, T. Harada, A. Umemura, H. Yamaguchi, H. Mukae, Dynamics of blood neutrophil-related indices during nivolumab treatment may be associated with response to salvage chemotherapy for non-small cell lung cancer: A hypothesisgenerating study, Thorac. Cancer. 10 (2019) 341-346. https://doi.org/10.1111/17597714.12952.

5. L. Horn, D.R. Spigel, E.E. Vokes, E. Holgado, N. Ready, M. Steins, E. Poddubskaya, H. Borghaei, E. Felip, L. Paz-Ares, A. Pluzanski, K.L. Reckamp, M.A. Burgio, M. Kohlhäeufl, D. Waterhouse, F. Barlesi, S. Antonia, O. Arrieta, J. Fayette, L. Crinò, N. Rizvi, M. Reck, M.D. Hellmann, W.J. Geese, A. Li, A. Blackwood-Chirchir, D. Healey, J. Brahmer, W.E.E. 
Eberhardt, Nivolumab versus docetaxel in previously treated patients with advanced non-small-cell lung cancer: Two-year outcomes from two randomized, open-label, phase III Trials (CheckMate 017 and CheckMate 057), J. Clin. Oncol. 35 (2017) 39243933. https://doi.org/10.1200/JCO.2017.74.3062.

6. N. Girard, P. Jacoulet, M. Gainet, R. Elleuch, D. Pernet, A. Depierre, J.C. Dalphin, V. Westeel, Third-line chemotherapy in advanced non-small cell lung cancer: Identifying the candidates for routine practice, J. Thorac. Oncol. 4 (2009) 1544-1549. https://doi.org/10.1097/JTO.0b013e3181bbf223.

7. F.A. Shepherd, J. Dancey, R. Ramlau, K. Mattson, R. Gralla, M. O’Rourke, N. Levitan, L. Gressot, M. Vincent, R. Burkes, S. Coughlin, Y. Kim, J. Berille, Prospective randomized trial of docetaxel versus best supportive care in patients with non-small-cell lung cancer previously treated with platinum- based chemotherapy, J. Clin. Oncol. 18 (2000) 20952103. https://doi.org/10.1200/JCO.2000.18.10.2095.

8. N. Hanna, F.A. Shepherd, F. V. Fossella, J.R. Pereira, F. Demarinis, J. Von Pawel, U. Gatzemeier, T.C.Y. Tsao, M. Pless, T. Muller, H.L. Lim, C. Desch, K. Szondy, R. Gervais, Shaharyar, C. Manegold, S. Paul, P. Paoletti, L. Einhorn, P.A. Bunn, Randomized phase III trial of pemetrexed versus docetaxel in patients with non-small-cell lung cancer previously treated with chemotherapy, J. Clin. Oncol. 22 (2004) 1589-1597. https://doi.org/10.1200/JCO.2004.08.163.

9. M.C. Garassino, O. Martelli, M. Broggini, G. Farina, S. Veronese, E. Rulli, F. Bianchi, A. Bettini, F. Longo, L. Moscetti, M. Tomirotti, M. Marabese, M. Ganzinelli, C. Lauricella, R. Labianca, I. Floriani, G. Giaccone, V. Torri, A. Scanni, S. Marsoni, Erlotinib versus docetaxel as second-line treatment of patients with advanced non-small-cell lung cancer and wild-type EGFR tumours (TAILOR): A randomised controlled trial, Lancet 
Oncol. 14 (2013) 981-988. https://doi.org/10.1016/S1470-2045(13)70310-3.

10. A. Ardizzoni, M. Tiseo, L. Boni, A.D. Vincent, R. Passalacqua, S. Buti, D. Amoroso, A. Camerini, R. Labianca, G. Genestreti, C. Boni, L. Ciuffreda, F. Di Costanzo, F. De Marinis, L. Crinò, A. Santo, A. Pazzola, F. Barbieri, N. Zilembo, I. Colantonio, C. Tibaldi, R. Mattioli, M.A. Cafferata, R. Camisa, E.F. Smit, Pemetrexed versus pemetrexed and carboplatin as second-line chemotherapy in advanced non-small-cell lung cancer: Results of the GOIRC 02-2006 randomized phase II study and pooled analysis with the NVALT7 trial, J. Clin. Oncol. 30 (2012) 4501-4507. https://doi.org/10.1200/JCO.2012.43.6758.

11. J. Davies, M. Patel, C. Gridelli, F. De Marinis, D. Waterkamp, M.E. McCusker, Real-world treatment patterns for patients receiving second-line and third-line treatment for advanced non-small cell lung cancer: A systematic review of recently published studies, PLoS One. 12 (2017). https://doi.org/10.1371/journal.pone.0175679.

12. M. Tone, T. Izumo, N. Awano, N. Kuse, M. Inomata, T. Jo, H. Yoshimura, S. Miyamoto, H. Kunitoh, Treatment effect and safety profile of salvage chemotherapy following immune checkpoint inhibitors in lung cancer, Lung Cancer Manag. 8 (2019) LMT12. https://doi.org/10.2217/Imt-2019-0001.

13. R. Kato, H. Hayashi, Y. Chiba, E. Miyawaki, J. Shimizu, T. Ozaki, D. Fujimoto, R. Toyozawa, A. Nakamura, T. Kozuki, K. Tanaka, S. Teraoka, K. Usui, K. Nishino, O. Hataji, K. Ota, N. Ebi, S. Saeki, Y. Akazawa, M. Okuno, N. Yamamoto, K. Nakagawa, Propensity score-weighted analysis of chemotherapy after PD-1 inhibitors versus chemotherapy alone in patients with non-small cell lung cancer (WJOG10217L), J. Immunother. Cancer. 8 (2020). https://doi.org/10.1136/jitc-2019-000350.

14. L.A. Emens, G. Middleton, The interplay of immunotherapy and chemotherapy: 
Harnessing potential synergies, Cancer Immunol. Res. 3 (2015) 436-443. https://doi.org/10.1158/2326-6066.CIR-15-0064.

15. A. Leonetti, B. Wever, G. Mazzaschi, Y.G. Assaraf, C. Rolfo, F. Quaini, M. Tiseo, E. Giovannetti, Molecular basis and rationale for combining immune checkpoint inhibitors with chemotherapy in non-small cell lung cancer, Drug Resist. Updat. 46 (2019) 100644. https://doi.org/10.1016/j.drup.2019.100644.

16. Z. Wang, P. Zhan, Y. Lv, K. Shen, Y. Wei, H. Liu, Y. Song, Prognostic role of pretreatment neutrophil-to-lymphocyte ratio in non-small cell lung cancer patients treated with systemic therapy: A meta-analysis, Transl. Lung Cancer Res. 8 (2019) 214-226. https://doi.org/10.21037/tlcr.2019.06.10.

17. G. Dixmier, B. Asselain, F. Barlesi, D. Debieuvre, C. Audigier Valette, A. Grö schel, S. Gütz, R. Liersch, D. Moro-Sibilot, H. Mü ller-Huesmann, M. Perol, C. Raspaud, C. Schulte, H. Schulz, C. Schumann, V. Allan, C. Calvet, K. Rothnie, V. Wü nsch, M. Sebastian, D. Talbot, S. Fish, T. Jin Ong, E. Flick, D. Waterhouse, Second-line (2L) realworld treatment (tx) patterns and outcomes in patients (pts) with advanced/metastatic non-small cell lung cancer (NSCLC) treated with first-line (1L) immuno-oncology (IO) monotherapy (mono tx), Abstr. B. 44th ESMO Congr. (ESMO 2019) 27 Sept. - 1 Oct. 2019, Barcelona, Spain. $30 \quad$ (2019) v614-v615. https://doi.org/10.1093/annonc/mdz260. 


\section{Acknowledgements}

We acknowledge all the Study Coordinators and Data Manager contributing to the administrative support and to the data collection for the CLARITY study at the participating centers.

\section{Funding}

This research did not receive any specific grant from funding agencies in the public, commercial, or not-for-profit sectors. 
Table 1 - Characteristics of patients from the CLARITY study.

\begin{tabular}{|c|c|}
\hline & $\begin{array}{l}N^{\circ} \text { of patients (\%) Overall population } \\
\qquad(\mathrm{N}=342)\end{array}$ \\
\hline Age (median, range) & $66(34-86)$ \\
\hline $\begin{array}{l}\text { Gender } \\
\text { Male } \\
\text { Female }\end{array}$ & $\begin{array}{l}210(61.4 \%) \\
132(38.6 \%)\end{array}$ \\
\hline $\begin{array}{l}\text { ECOG PS at CT start } \\
0 \\
1 \\
2 \\
\text { NA }\end{array}$ & $\begin{array}{l}61(17.8 \%) \\
200(58.5 \%) \\
77(22.5 \%) \\
4(1.2 \%)\end{array}$ \\
\hline $\begin{array}{l}\text { Stage at diagnosis } \\
\text { I } \\
\text { II } \\
\text { III } \\
\text { IV }\end{array}$ & $\begin{array}{l}17(5 \%) \\
16(4.7 \%) \\
64(18.8 \%) \\
243(71.1 \%)\end{array}$ \\
\hline $\begin{array}{l}\text { Histotype } \\
\text { Adenocarcinoma } \\
\text { Squamous cell carcinoma } \\
\text { NAS/other }\end{array}$ & $\begin{array}{l}243 \\
84 \\
15\end{array}$ \\
\hline $\begin{array}{l}\text { Treatment line for } \mathbf{C T} \\
\text { II line } \\
\text { III line } \\
\geq \text { IV line }\end{array}$ & $\begin{array}{l}86(25.1 \%) \\
197(57.6 \%) \\
59(17.3 \%)\end{array}$ \\
\hline $\begin{array}{l}\text { Type of CKI treatment prior to CT } \\
\text { Nivolumab } \\
\text { Pembrolizumab } \\
\text { Atezolizumab } \\
\text { Other* }\end{array}$ & $\begin{array}{l}219(64.0 \%) \\
91(26.6 \%) \\
21(6.1 \%) \\
11(3.3 \%)\end{array}$ \\
\hline $\begin{array}{l}\text { Best response to prior CKI } \\
\text { Complete response } \\
\text { Partial response } \\
\text { Stable disease } \\
\text { Progressive disease }\end{array}$ & $\begin{array}{l}0 \\
72(21.1 \%) \\
109(31.8 \%) \\
161(47.1 \%)\end{array}$ \\
\hline $\begin{array}{l}\text { CT regimen } \\
\text { Platinum combination } \\
\text { Gemcitabine alone }\end{array}$ & $\begin{array}{l}100(29.2 \%) \\
64(18.7 \%)\end{array}$ \\
\hline
\end{tabular}


Taxane-based

Vinorelbine alone

Other
$133(38.9 \%)$

$46(13.5 \%)$

$10(2.9 \%)$

NA = not available; ECOG PS = Eastern European Oncology Group Performance Status; CT = chemotherapy; $\mathrm{CKI}=$ immune checkpoint inhibitor

*other CKI included: avelumab, durvalumab, ipilimumab plus nivolumab, tremelimumab plus durvalumab (clinical trials were allowed). 
Table 2 - Univariate analyses for overall survival and progression-free survival to chemotherapy. 


\begin{tabular}{|c|c|c|c|c|}
\hline & OS from CT & $\boldsymbol{P}$ & PFS from CT & $\boldsymbol{P}$ \\
\hline $\begin{array}{l}\text { GENDER } \\
\text { Male } \\
\text { Female } \\
\end{array}$ & $\begin{array}{l}5.7(4.9-6.5) \\
9.5(7.6-11.3) \\
\end{array}$ & $\begin{array}{l}P=0.01 \\
1.44(1.08-1.91)\end{array}$ & $\begin{array}{l}4.0(3.0-5.0) \\
4.4(3.3-5.5) \\
\end{array}$ & $\begin{array}{l}P=0.69 \\
1.05(0.81-1.37)\end{array}$ \\
\hline $\begin{array}{l}\text { AGE } \\
\geq 65 \text { years } \\
<65 \text { years }\end{array}$ & $\begin{array}{l}6.8(5.2-8.4) \\
6.4(4.8-8.0)\end{array}$ & $\begin{array}{l}P=0.89 \\
0.98(0.75-1.28)\end{array}$ & $\begin{array}{l}4.4(3.5-5.3) \\
3.4(2.5-4.3)\end{array}$ & $\begin{array}{l}P=0.31 \\
0.88(0.68-1.13)\end{array}$ \\
\hline $\begin{array}{l}\text { SMOKING HABITS } \\
\text { Current } \\
\text { Never } \\
\text { Former }\end{array}$ & $\begin{array}{l}6.2(4.4-8.0) \\
9.6(6.4-12.8) \\
6.2(4.8-7.6) \\
\end{array}$ & $\begin{array}{l}P=0.09 \\
\text { (current vs never) } \\
1.47(0.96-2.25) P=0.08 \\
\text { (former vs never) } \\
1.53(1.04-2.24) P=0.03\end{array}$ & $\begin{array}{l}4.1(3.0-5.2) \\
4.4(3.1-5.7) \\
3.9(2.9-4.9) \\
\end{array}$ & $\begin{array}{l}P=0.86 \\
\text { (current vs never) } \\
0.90(0.61-1.31) P=0.58 \\
\text { (former vs never) } \\
0.93(0.67-1.31) P=0.69\end{array}$ \\
\hline $\begin{array}{l}\text { HISTOLOGY } \\
\text { SCC } \\
\text { ADK } \\
\text { NOS } \\
\text { other }\end{array}$ & $\begin{array}{l}5.5(4.6-6.4) \\
7.3(5.8-8.8) \\
8.0(4.7-11.3) \\
3.9(0-8.2)\end{array}$ & $\begin{array}{l}P=0.55 \\
\text { (SCC vs ADK) } \\
1.23(0.91-1.65) P=0.19 \\
\text { (NAS vs ADK) } \\
0.94(0.48-1.85) P=0.86 \\
\text { (other vs ADK) } \\
1.48(0.37-6.01) P=0.58\end{array}$ & $\begin{array}{l}3.8(2.4-5.2) \\
4.4(3.6-5.2) \\
3.1(1.4-4.8) \\
2.1(1.5-2.7)\end{array}$ & $\begin{array}{l}P=0.55 \\
\text { (SCC vs ADK) } \\
1.31(0.98-1.75) P=0.06 \\
\text { (NAS vs ADK) } \\
1.17(0.61-2.21) P=0.64 \\
\text { (other vs ADK) } \\
1.20(0.30-4.86) P=0.80\end{array}$ \\
\hline $\begin{array}{l}\text { ECOG PS at CT } \\
0 \\
1 \\
2\end{array}$ & $\begin{array}{l}11.4(5.0-17.8) \\
7.2(5.8-8.6) \\
3.0(2.3-3.7)\end{array}$ & $\begin{array}{l}P=0.0001 \\
(1 \text { vs } 0) \\
1.93(1.26-2.94) P= \\
0.002 \\
(2 \text { vs } 0) \\
3.80(2.39-6.03) P< \\
0.0001\end{array}$ & $\begin{array}{l}5.7(4.7-6.7) \\
4.3(3.5-5.1) \\
2.1(1.8-2.4)\end{array}$ & $\begin{array}{l}P<0.0001 \\
(1 \text { vs } 0) \\
1.28(0.89-1.82) P=0.18 \\
(2 \text { vs } 0) \\
2.29(1.53-3.43) P< \\
0.0001\end{array}$ \\
\hline $\begin{array}{l}\text { PD-L1 } \\
\geq 1 \% \\
<1 \%\end{array}$ & $\begin{array}{l}8.4(5.8-11.0) \\
7.0(2.6-11.4)\end{array}$ & $\begin{array}{l}P=0.51 \\
0.86(0.56-1.34)\end{array}$ & $\begin{array}{l}5.4(4.6-6.2) \\
4.0(2.8-5.2)\end{array}$ & $\begin{array}{l}P=0.49 \\
0.86(0.57-1.31)\end{array}$ \\
\hline $\begin{array}{l}\text { PD-L1 } \\
\geq 50 \% \\
<50 \%\end{array}$ & $\begin{array}{l}8.4(7.3-9.5) \\
7.0(3.7-10.3)\end{array}$ & $\begin{array}{l}P=0.34 \\
0.79(0.49-1.27)\end{array}$ & $\begin{array}{l}5.3(4.1-6.5) \\
4.6(3.0-6.2)\end{array}$ & $\begin{array}{l}P=0.92 \\
1.02(0.67-1.55)\end{array}$ \\
\hline $\begin{array}{l}\text { CT LINE } \\
2 \\
3 \\
\geq 4\end{array}$ & $\begin{array}{l}8.4(5.6-11.2) \\
5.8(4.6-7.0) \\
6.4(3.5-9.3)\end{array}$ & $\begin{array}{l}P=0.12 \\
(3 \text { vs } 2) \\
1.38(0.97-1.96) P=0.07 \\
(4 \text { vs } 2) \\
1.08(0.70-1.66) P=0.74\end{array}$ & $\begin{array}{l}5.1(3.6-6.6) \\
4.0(3.1-4.9) \\
2.8(1.6-4.2)\end{array}$ & $\begin{array}{l}P=0.44 \\
(3 \text { vs } 2) \\
1.18(0.85-1.62) P=0.32 \\
(4 \text { vs } 2) \\
1.28(0.87-1.88) P=0.21\end{array}$ \\
\hline $\begin{array}{l}\text { CKI TYPE } \\
\text { Anti-PD-L1 } \\
\text { Anti-PD-1 }\end{array}$ & $\begin{array}{l}8.8(0.3-17.3) \\
6.4(5.3-7.5)\end{array}$ & $\begin{array}{l}P=0.16 \\
0.68(0.39-1.17)\end{array}$ & $\begin{array}{l}5.5(4.6-6.4) \\
3.4(2.7-4.1)\end{array}$ & $\begin{array}{l}P=0.58 \\
0.87(0.52-1.44)\end{array}$ \\
\hline $\begin{array}{l}\text { ORR at CKI } \\
\text { Yes } \\
\text { No }\end{array}$ & $\begin{array}{l}9.6(7.7-11.5) \\
6.1(5.1-7.1)\end{array}$ & $\begin{array}{l}P=0.01 \\
0.65(0.46-0.92)\end{array}$ & $\begin{array}{l}4.8(3.5-6.1) \\
3.9(3.2-4.6)\end{array}$ & $\begin{array}{l}P=0.50 \\
0.90(0.66-1.23)\end{array}$ \\
\hline $\begin{array}{l}\text { DCR at CKI } \\
\text { Yes } \\
\text { No } \\
\end{array}$ & $\begin{array}{l}8.3(5.9-10.6) \\
5.7(4.8-6.6)\end{array}$ & $\begin{array}{l}P=0.005 \\
0.68(0.52-0.89)\end{array}$ & $\begin{array}{l}4.6(3.9-5.2) \\
2.9(2.1-5.2)\end{array}$ & $\begin{array}{l}P=0.01 \\
0.73(0.56-0.94)\end{array}$ \\
\hline $\begin{array}{l}\text { NLR at CKI start } \\
\geq 4 \\
<4\end{array}$ & $\begin{array}{l}6.2(4.2-8.2) \\
8.3(6.0-10.6)\end{array}$ & $\begin{array}{l}P=0.014 \\
1.46(1.08-1.98)\end{array}$ & $\begin{array}{l}3.9(2.8-5.0) \\
4.4(3.6-5.2)\end{array}$ & $\begin{array}{l}P=0.35 \\
1.15(0.86-1.52)\end{array}$ \\
\hline
\end{tabular}




\begin{tabular}{|c|c|c|c|c|}
\hline $\begin{array}{l}\text { NLR at CKI end } \\
\geq 4 \\
<4\end{array}$ & $\begin{array}{l}6.2(4.1-8.3) \\
7.7(5.3-10.1)\end{array}$ & $\begin{array}{l}P=0.054 \\
1.34(0.99-1.80)\end{array}$ & $\begin{array}{l}3.8(2.4-5.2) \\
4.6(3.8-5.4)\end{array}$ & $\begin{array}{l}P=0.21 \\
1.20(0.90-1.59)\end{array}$ \\
\hline $\begin{array}{l}\text { NLR delta } \\
\text { Increased-stable } \\
\text { decreased }\end{array}$ & $\begin{array}{l}8.0(5.5-10.5) \\
6.2(4.9-7.5)\end{array}$ & $\begin{array}{l}P=0.53 \\
1.09(0.83-1.45)\end{array}$ & $\begin{array}{l}4.4(3.0-5.8) \\
4.0(3.2-4.8)\end{array}$ & $\begin{array}{l}P=0.15 \\
1.22(0.93-1.59)\end{array}$ \\
\hline $\begin{array}{l}\text { LDH at CKI start } \\
<250 \mathrm{U} / \mathrm{I} \\
\geq 250 \mathrm{U} / \mathrm{I}\end{array}$ & $\begin{array}{l}7.0(3.1-10.9) \\
6.9(5.1-8.6)\end{array}$ & $\begin{array}{l}P=0.77 \\
(>250 \text { vs }<250) \\
1.06(0.71-1.58)\end{array}$ & $\begin{array}{l}4.0(1.6-6.4) \\
3.5(2.4-4.6)\end{array}$ & $\begin{array}{l}P=0.13 \\
(>250 \text { vs }<250) \\
1.33(0.92-1.93)\end{array}$ \\
\hline $\begin{array}{l}\text { LDH at IT end } \\
\geq 250 \mathrm{U} / \mathrm{I} \\
<250 \mathrm{U} / \mathrm{I}\end{array}$ & $\begin{array}{l}6.8(5.0-8.6) \\
10.2(6.3-14.1)\end{array}$ & $\begin{array}{l}P=0.45 \\
1.22(0.73-2.05)\end{array}$ & $\begin{array}{l}3.4(2.4-4.39) \\
5.7(3.7-7.7)\end{array}$ & $\begin{array}{l}P=0.09 \\
1.49(0.94-2.38)\end{array}$ \\
\hline $\begin{array}{l}\text { LDH delta } \\
\text { Increased-stable } \\
\text { decreased }\end{array}$ & $\begin{array}{l}7.6(5.0-10.3) \\
7.4(5.0-9.8)\end{array}$ & $\begin{array}{l}P=0.79 \\
1.05(0.72-1.53)\end{array}$ & $\begin{array}{l}4.3(2.5-6.1) \\
3.6(2.5-4.7)\end{array}$ & $\begin{array}{l}P=0.56 \\
1.11(0.78-1.57)\end{array}$ \\
\hline $\begin{array}{l}\mathrm{LDH} \text { at } \mathrm{CT} \\
\text { initiation } \\
\geq 250 \mathrm{U} / \mathrm{I} \\
<250 \mathrm{U} / \mathrm{l}\end{array}$ & $\begin{array}{l}6.3(4.9-7.7) \\
9.9(5.0-14.8)\end{array}$ & $\begin{array}{l}P=0.38 \\
1.24(0.77-2.00)\end{array}$ & $\begin{array}{l}3.1(2.0-4.2) \\
7.9(3.6-12.2)\end{array}$ & $\begin{array}{l}P=0.02 \\
1.72(1.09-2.71)\end{array}$ \\
\hline $\begin{array}{l}\text { ANC delta } \\
\text { Increased-stable } \\
\text { decrease }\end{array}$ & $\begin{array}{l}8.0(5.1-10.9) \\
6.5(5.2-7.8)\end{array}$ & $\begin{array}{l}P=0.53 \\
1.09(0.83-1.45)\end{array}$ & $\begin{array}{l}4.6(3.7-5.5) \\
3.6(2.4-4.8)\end{array}$ & $\begin{array}{l}P=0.09 \\
1.25(0.96-1.63)\end{array}$ \\
\hline $\begin{array}{l}\text { PFS at CKI } \\
\geq 4 \text { months } \\
<4 \text { months }\end{array}$ & $\begin{array}{l}7.7(5.3-10.1) \\
5.9(4.5-7.3)\end{array}$ & $\begin{array}{l}P=0.007 \\
0.69(0.53-0.90)\end{array}$ & $\begin{array}{l}4.6(4.0-5.2) \\
3.0(2.3-3.7)\end{array}$ & $\begin{array}{l}P=0.03 \\
0.76(0.59-0.98)\end{array}$ \\
\hline $\begin{array}{l}\text { TOXICITY from CKI } \\
\text { Yes } \\
\text { No }\end{array}$ & $\begin{array}{l}6.8(4.9-8.7) \\
6.4(5.0-7.8)\end{array}$ & $\begin{array}{l}P=0.77 \\
0.96(0.74-1.26)\end{array}$ & $\begin{array}{l}4.4(3.5-5.3) \\
3.8(3.0-4.6)\end{array}$ & $\begin{array}{l}P=0.62 \\
0.94(0.73-1.21)\end{array}$ \\
\hline $\begin{array}{l}\text { G3-G4 TOXICITY } \\
\text { CKI } \\
\text { Yes } \\
\text { No }\end{array}$ & $\begin{array}{l}9.9(8.0-11.8) \\
6.3(5.2-7.4)\end{array}$ & $\begin{array}{l}P=0.19 \\
0.72(0.45-1.17)\end{array}$ & $\begin{array}{l}4.1(3.4-4.8) \\
3.3(1.4-5.3)\end{array}$ & $\begin{array}{l}P=0.63 \\
0.90(0.59-1.38)\end{array}$ \\
\hline $\begin{array}{l}\text { TOXICITY from CT } \\
\text { Yes } \\
\text { no }\end{array}$ & $\begin{array}{l}7.2(5.5-8.9) \\
6.2(3.8-8.6)\end{array}$ & $\begin{array}{l}P=0.52 \\
0.91(0.69-1.20)\end{array}$ & $\begin{array}{l}4.9(4.0-5.8) \\
3.0(2.1-3.9)\end{array}$ & $\begin{array}{l}P=0.006 \\
0.70(0.54-0.90)\end{array}$ \\
\hline $\begin{array}{l}\text { PLATINUM based } \\
\text { combinations } \\
\text { Yes } \\
\text { No }\end{array}$ & $\begin{array}{l}8.4(5.2-11.6) \\
6.2(5.1-7.3)\end{array}$ & $\begin{array}{l}P=0.03 \\
0.71(0.51-0.97)\end{array}$ & $\begin{array}{l}4.9(3.8-6.0) \\
3.8(2.9-4.6)\end{array}$ & $\begin{array}{l}P=0.56 \\
0.92(0.69-1.22)\end{array}$ \\
\hline
\end{tabular}

OS = overall survival; PFS = progression free survival; NA = not available; $E C O G$ PS = Eastern European Oncology Group Performance Status; $\mathrm{CT}=$ chemotherapy; $\mathrm{CKI}=$ immune checkpoint inhibitor; $S C C=$ squamous cell carcinoma; $A D K=$ adenocarcinoma; NAS = not otherwise specified; $\mathrm{NLR}=$ neutrophil to lymphocyte ratio; $\mathrm{ORR}=$ objective response rate; $\mathrm{DCR}=$ disease control rate; $\mathrm{LDH}=$ lactate dehydrogenase; $\mathrm{ANC}=$ absolute neutrophil count; G3-G4 = grade 3-4 
Table 3 - Multivariate analyses for overall survival and progression-free survival to chemotherapy.

\begin{tabular}{|l|l|l|}
\hline & \multicolumn{1}{|c|}{ OS } & PFS \\
\hline Variable & HR (95\% CI) & HR (95\% CI) \\
\hline $\begin{array}{l}\text { GENDER } \\
\text { Male vs female }\end{array}$ & $1.54(1.15-2.06) p=0.004$ & $p=\mathrm{NS}$ \\
\hline AGE $(\geq 65$ vs $<65)$ & $p=\mathrm{NS}$ & $p=\mathrm{NS}$ \\
\hline SMOKING HABITS & $p=\mathrm{NS}$ & $p=\mathrm{NS}$ \\
\hline ECOG PS at CT & $p=0.0001$ & $p<0.0001$ \\
$(1$ vs 0$)$ & $1.93(1.26-2.95) p=0.002$ & $1.27(0.88-1.83) p=0.19$ \\
$(2$ vs 0$)$ & $3.93(2.47-6.26) p<$ & $2.13(1.40-3.22) p=$ \\
& 0.0001 & 0.0001 \\
\hline CKI LINE & $p=\mathrm{NS}$ & $p=\mathrm{NS}$ \\
\hline CKI type & $p=\mathrm{NS}$ & $p=\mathrm{NS}$ \\
\hline DCR at IT (yes vs no) & $0.68(0.52-0.90) p=0.006$ & $0.76(0.59-0.99) p=0.04$ \\
\hline ORR at IT & $p=\mathrm{NS}$ & $p=\mathrm{NS}$ \\
\hline PFS at IT $>4$ months & $p=\mathrm{NS}$ & $p=\mathrm{NS}$ \\
\hline TOXICITY from CT (yes vs no) & $p=\mathrm{NS}$ & $0.75(0.58-0.98) p=0.036$ \\
\hline
\end{tabular}

OS = overall survival; PFS = progression free survival; $\mathrm{Cl}=$ confidence interval; $\mathrm{ECOG} P \mathrm{PS}=$ European Oncology Group Performance Status; CT = chemotherapy; CKI = immune checkpoint inhibitor; DCR = disease control rate; $\mathrm{ORR}=$ objective response rate

Figure legends

Figure 1 - Kaplan-Meier overall survival (a) and progression free survival (b) curves of the overall study population to chemotherapy

Figure 2 - Overall survival curves according to the "Post-ICl score" with three-risk group stratification

Figure 3 - Overall survival-2 curve of the overall population (outcome to the sequence of immune checkpoint inhibitor and chemotherapy) 